\title{
Prediction of metabolic status of dairy cows in early lactation with on-farm cow data and machine learning algorithms
}

\author{
Wei Xu, ${ }^{1,2}$ Ariette T. M. van Knegsel, ${ }^{1}$ Jacques J. M. Vervoort, ${ }^{2}$ Rupert M. Bruckmaier, ${ }^{3}$ Renny J. van Hoeij, ${ }^{1}$ \\ Bas Kemp, ${ }^{1}$ and Edoardo Saccenti ${ }^{4 *}$ \\ ${ }^{1}$ Adaptation Physiology Group, Department of Animal Sciences, Wageningen University and Research, PO Box 338, 6700 AH, Wageningen, \\ the Netherlands \\ ${ }^{2}$ Laboratory of Biochemistry, Wageningen University and Research, PO Box 338, $6700 \mathrm{AH}$, Wageningen, the Netherlands \\ ${ }^{3}$ Veterinary Physiology, Vetsuisse Faculty, University of Bern, Bremgartenstrasse 109a, CH-3001, Bern, Switzerland \\ ${ }^{4}$ Laboratory of Systems and Synthetic Biology, Wageningen University and Research, Stippeneng 4, 6708 WE, Wageningen, the Netherlands
}

\section{ABSTRACT}

Metabolic status of dairy cows in early lactation can be evaluated using the concentrations of plasma $\beta$-hydroxybutyrate (BHB), free fatty acids (FFA), glucose, insulin, and insulin-like growth factor 1 (IGF-1). These plasma metabolites and metabolic hormones, however, are difficult to measure on farm. Instead, easily obtained on-farm cow data, such as milk production traits, have the potential to predict metabolic status. Here we aimed (1) to investigate whether metabolic status of individual cows in early lactation could be clustered based on their plasma values and (2) to evaluate machine learning algorithms to predict metabolic status using on-farm cow data. Through lactation wk 1 to 7 , plasma metabolites and metabolic hormones of 334 cows were measured weekly and used to cluster each cow into 1 of 3 clusters per week. The cluster with the greatest plasma BHB and FFA and the lowest plasma glucose, insulin, and IGF-1 was defined as poor metabolic status; the cluster with the lowest plasma $\mathrm{BHB}$ and FFA and the greatest plasma glucose, insulin, and IGF-1 was defined as good metabolic status; and the intermediate cluster was defined as average metabolic status. Most dairy cows were classified as having average or good metabolic status, and a limited number of cows had poor metabolic status (10-50 cows per lactation week). On-farm cow data, including dry period length, parity, milk production traits, and body weight, were used to predict good or average metabolic status with 8 machine learning algorithms. Random Forest (error rate ranging from 12.4 to $22.6 \%$ ) and Support Vector Machine (SVM; error rate ranging from 12.4 to $20.9 \%$ ) were the top 2 best-performing algorithms to predict metabolic status using on-farm cow data. Ran-

Received October 3, 2018.

Accepted June 5, 2019.

*Corresponding author: esaccenti@gmail.com dom Forest had a higher sensitivity (range: 67.8-82.9\% during wk 1 to 7 ) and negative predictive value (range: 89.5-93.8\%) but lower specificity (range: 76.7-88.5\%) and positive predictive value (range: $58.1-78.4 \%$ ) than SVM. In Random Forest, milk yield, fat yield, protein percentage, and lactose yield had important roles in prediction, but their rank of importance differed across lactation weeks. In conclusion, dairy cows could be clustered for metabolic status based on plasma metabolites and metabolic hormones. Moreover, on-farm cow data can predict cows in good or average metabolic status, with Random Forest and SVM performing best of all algorithms.

Key words: energy metabolism, cattle, cluster analysis, Random Forest

\section{INTRODUCTION}

In early lactation, high-yielding dairy cows suffer from body fat mobilization (Bell, 1995; Ingvartsen and Andersen, 2000) and drastic metabolic changes (Grummer, 1993; Drackley, 1999). Effective and accurate detection of metabolic status of dairy cows could benefit cow health and welfare by application of dietary and management strategies. Plasma metabolites and metabolic hormones have been used to indicate metabolic status of cows (Butler, 2003; Bernabucci et al., 2005; Pezeshki et al., 2007). Poor metabolic status is related not only to increased plasma concentration of BHB and free fatty acids (FFA; also referred to as nonesterified fatty acids) and a decreased concentration of metabolic hormones, such as plasma insulin and IGF-1 (Dann et al., 2005; de Feu et al., 2009), but also to an increased incidence of metabolic disorders such as ketosis and fatty liver (Grummer, 1993; Ingvartsen et al., 2003; Seifi et al., 2011). Moreover, poor metabolic status in early lactation, indicated by elevated plasma nonesterified fatty acids or elevated BHB concentration, was associated with an increased risk for displaced abomasum, 
culling, and reduced reproductive success (as reviewed by McArt et al., 2013). In addition, incidence of metabolic problems in early lactation has been related to an altered lactation curve with a lower peak milk yield and reduced 305-d milk production (Hostens et al., 2012). Blood sampling, however, is an invasive method that has limited applicability on the farm. A possible alternative is to predict metabolic status with on-farm cow data that are easily obtained-for example, BW, milk production traits, and parity. Milk production traits have been used to predict plasma BHB (Nielsen et al., 2005; van Knegsel et al., 2010) and energy status at herd level of cows (Løvendahl et al., 2010). We hypothesize that on-farm cow data can predict metabolic status of dairy cows in early lactation.

The machine learning method uses statistical techniques to predict cow performance or disease events using large data sets (Shahinfar et al., 2012; Hempstalk et al., 2015). On farm, available cow data usually include a series of correlated variables; for example, fat yield is correlated with milk yield (Wilmink, 1987; Xu et al., 2018). Machine learning algorithms, however, can deal with complicated correlations caused by an ever-increasing number of variables (Dormann et al., 2013). For example, Decision Tree has good predictive performance in correlation-based variable selection (Hall, 1999), and Bayesian inference could mitigate the effect of correlations among a set of variables (Liechty et al., 2004). Machine learning algorithms, such as naive Bayes, random forest, and artificial neural networks (ANN), have been used to predict milk yield (Gianola et al., 2011), breeding values (Shahinfar et al., 2012), and reproductive performance (Shahinfar et al., 2014; Hempstalk et al., 2015) and to identify mastitis (Cavero et al., 2008; Sun et al., 2010) in dairy cows. Additionally, cluster analysis was used to define metabolic status in dairy cows in early lactation (Tremblay et al., 2018; van Hoeij et al., 2019). To our knowledge, however, research on the application of machine learning algorithms to predict metabolic status of dairy cows in early lactation using on-farm cow data has never been published. In this study, we aimed (1) to define metabolic status of dairy cows through cluster analysis based on their plasma metabolites and metabolic hormones during lactation wk 1 to 7 and (2) to predict metabolic status of those cows using on-farm cow data through machine learning algorithms.

\section{MATERIALS AND METHODS}

\section{Data and Animals}

Data were collected from 2 earlier studies with protocol number 2010026 (study 1; van Knegsel et al., 2014;
Chen et al., 2016) and 2014125 (study 2; van Hoeij et al., 2017). The experimental protocols were approved by the Institutional Animal Care and Use Committee of Wageningen University and were conducted at Dairy Campus research herd (WUR Livestock Research, Lelystad, the Netherlands). In study 1, 168 HolsteinFriesian cows were assigned randomly to 1 of 3 groups with a $0-, 30-$, or 60-d dry period (DP): 56 cows with a 0 -d DP (20 cows in parity $2 ; 36$ cows in parity $\geq 3$ ), 56 cows with a $30-d$ DP (20 cows in parity $2 ; 36$ cows in parity $\geq 3$ ), and 56 cows with a 60 -d DP (20 cows in parity $2 ; 36$ cows in parity $\geq 3$ ). After 1 lactation within the experiment, 130 cows were monitored for a second lactation within study 1 (Chen et al., 2016). In study 2, 127 Holstein-Friesian cows were assigned randomly to 1 of 2 groups with a $0-$ or 30-d DP: 84 cows with a 0 -d DP (40 cows in parity $2 ; 44$ cows in parity $\geq 3$ ) and 43 cows with a 30 -d DP (19 cows in parity $2 ; 24$ cows in parity $\geq 3$ ). During all lactation stages in both studies 1 and 2, cows were housed in a freestall with slatted floor and cubicles and were milked twice daily. Before calving, dry cows were fed a dry cow diet that consisted of grass silage, corn silage, wheat straw, rapeseed meal, urea, and vitamins and minerals (5.4 MJ of $\mathrm{NE}_{\mathrm{L}} / \mathrm{kg}$ of $\mathrm{DM})$, whereas lactating cows were fed a lactation diet supporting $25 \mathrm{~kg}$ of milk. All cows were fed $1 \mathrm{~kg} / \mathrm{d}$ of glucogenic or lipogenic concentrate from $10 \mathrm{~d}$ before the expected calving date. Postpartum, the experimental concentrate supply was increased in increments of 0.5 $\mathrm{kg} / \mathrm{d}$ until a level of $8.5 \mathrm{~kg} / \mathrm{d}$ was reached. Details on diet composition were presented earlier (van Knegsel et al., 2014; Chen et al., 2016; van Hoeij et al., 2017).

\section{Measurements}

Body weight and milk yield were recorded daily and averaged per week. Milk fat, protein, and lactose percentage and SCC were analyzed per cow per week (ISO, 2013; Qlip, Zutphen, the Netherlands). Fat- and protein-corrected milk (FPCM) was calculated as (CVB, 2011)

$$
\begin{aligned}
& \text { FPCM }(\mathrm{kg})=(0.337+0.116 \times \text { fat percentage } \\
& +0.06 \times \text { protein percentage }) \times \text { milk yield }(\mathrm{kg}) .
\end{aligned}
$$

During wk 1 to 7 postpartum, $10 \mathrm{~mL}$ of blood was sampled every Thursday morning from the coccygeal vein into evacuated EDTA tubes (Vacuette, Greiner BioOne, Kremsmunster, Austria). Blood samples were kept on ice before centrifugation for plasma isolation $\left(3,000 \times g\right.$ for $\left.15 \mathrm{~min}, 4^{\circ} \mathrm{C}\right)$. Plasma samples were stored at $-20^{\circ} \mathrm{C}$ before analysis. Plasma analysis has been previously described (Vicari et al., 2008; Graber 
Table 1. Number of dairy cows with complete blood and milk observations in studies 1 and 2 through lactation wk 1 to 7

\begin{tabular}{|c|c|c|c|c|c|c|c|}
\hline \multirow[b]{2}{*}{ Study $^{1}$} & \multicolumn{7}{|c|}{ Lactation week } \\
\hline & 1 & 2 & 3 & 4 & 5 & 6 & 7 \\
\hline \multicolumn{8}{|l|}{ Study 1} \\
\hline First lactation & 58 & 89 & 92 & 92 & 89 & 89 & 90 \\
\hline Second lactation & 71 & 104 & 99 & 99 & 91 & 88 & 86 \\
\hline Study 2 & 91 & 122 & 120 & 119 & 121 & 122 & 122 \\
\hline Total & 220 & 315 & 311 & 310 & 301 & 299 & 298 \\
\hline
\end{tabular}

${ }^{1}$ The experimental design, dry period length, and diet in study 1 first lactation were described by van Knegsel et al. (2014), in study 1 second lactation were described by Chen et al. (2016), and in study 2 were described by van Hoeij et al. (2017).

et al., 2012). In short, the concentration of BHB was measured with kit no. RB1007 (Randox Laboratories, Ibach, Switzerland), FFA with kit no. 994-75409 (Wako Chemicals, Neuss, Germany), glucose with kit no. 61269 (BioMerieux, Marcy l'Etoile, France; Graber et al., 2012), insulin with kit no. PI-12K (EMD Millipore Corp., Billerica, MA), and IGF-1 with kit no. A15729 (Beckman Coulter, Fullerton, CA; Vicari et al., 2008).

\section{Data Transformation}

Plasma glucose displayed a normal distribution in all lactation weeks. Raw data of FFA, BHB, insulin, and IGF-1 were first log-transformed to correct for skewness.

\section{Principal Component Analysis and Correlation Analysis}

Principal component analysis (PCA) was performed to transform the data of 5 plasma metabolites and hormones into several orthogonal principal components (PC; Borcard et al., 2011) for visualization and interpretation purposes. Data were centered and scaled to unit variance before analysis. The number of PC to retain was determined using the "elbow rule" (Johnson and Wichern, 2002). The bi-plot (by 2 dimensions) was used to investigate the patterns of variation of data and visualize the clustering with respect to different metabolic statuses. The correlation coefficient among 5 plasma metabolites and hormones was determined by Pearson correlation.

\section{Cluster Analysis}

In the current study, we assumed that the different metabolic status of dairy cows could be grouped through cluster analysis per lactation week. From studies 1 and 2, a total of 220,315, 311, 310, 301, 299, and 298 cows with complete records for both blood and milk were used through lactation wk 1, 2, 3, 4, 5, 6 , and 7 , respectively (Table 1 ). To assign dairy cows to metabolic status in each lactation week, $k$-means cluster analysis was applied on weekly plasma BHB, FFA, glucose, insulin, and IGF-1. Briefly, prerequisite cluster number $k$ was determined using the "average silhouette" method (Rousseeuw, 1987). Then, a set of $n$ samples $X_{(1,2, \ldots, i, i+1, \ldots, n)}$ was grouped into different clusters $C_{j}(1,2, \ldots, k)$; the mean $\left(\mu_{k}\right)$ of all samples in each cluster was called the cluster centroid. Based on an iteration (maximum number of 10 ) that puts 1 sample into a cluster each time, the $k$-means algorithm aims to choose the centroid with a minimized withincluster sum of squared Euclidean distance among each observation. Average values for plasma BHB, FFA, glucose, insulin, and IGF-1 were calculated per cluster per lactation week and over all 7 lactation weeks.

\section{Definition of Metabolic Clusters}

Labeling of clusters for poor, average, or good metabolic status was based on average value within a cluster for concentrations of plasma BHB, FFA, glucose, insulin, and IGF-1 relative to the other clusters within the same lactation week. The cluster with the greatest plasma BHB and FFA and the lowest plasma glucose, insulin, and IGF-1 was defined as poor metabolic status; the cluster with the lowest plasma BHB and FFA and the greatest plasma glucose, insulin, and IGF-1 was defined as good metabolic status; and the intermediate cluster was defined as average metabolic status.

\section{Machine Learning Algorithms}

Machine learning algorithms were evaluated to predict cows in poor, average, or good metabolic status. Preliminary analysis indicated a limited number of cows in the poor metabolic status group; therefore, we 
built further classifiers to predict cows in either good or average metabolic status. In each lactation week, models were trained by 8 machine learning algorithms using on-farm cow data with 13 features, including BW, DP, parity, milk yield, milk yield standard deviation, fat percentage, protein percentage, lactose percentage, FPCM, SCC, fat yield, protein yield, and lactose yield. Features were presented as an average per week, except milk yield, which was included both as an average per week and as a standard deviation of milk yield per week. In the current study, cow in one lactation was regarded as independent of the same cow in another lactation. Evaluating several algorithms on a specific task is a common practice in machine learning because performance of algorithm may depend on features, sample size, structure, and other characteristics of the data set. In this study, 8 widely used machine learning algorithms were evaluated, including Decision Tree, Naive Bayes, Bayesian Network, Support Vector Machine, ANN, Bootstrap Aggregation, Random Forest, and K-Nearest Neighbor. All methods were used with default parameters. A brief explanation of each algorithm is presented in the Appendix together with the corresponding parameter settings.

\section{Model Evaluation}

In each lactation week, models trained with 8 machine learning algorithms were evaluated through 10fold cross-validation. Briefly, in 10-fold cross-validation, $10 \%$ of the samples in the whole data set were kept as a testing data set and the rest of the samples (90\%) were used to train the model. Through lactation wk 1 to 7 , in total $29,65,64,63,56,51$, and 51 cows were in the data set with 2 separate lactations. A cow was only used once per loop of 10-fold cross-validation in order to avoid the same cow being in both the test and train data sets at the same time with a different lactation number. One loop ended until all samples were used exactly once in testing. For each machine learning algorithm, each loop of cross-validation repeated 500 time. Error rate is a priori value to evaluate the predictive performance of machine learning algorithms in each lactation week. To predict cows with 2 metabolic statuses, the error rate is defined as the ratio of false positives and false negatives. To predict cows with 3 metabolic statuses,

$$
\begin{gathered}
\text { error rate }= \\
1-(\text { sum of corrected prediction/sample size }) \\
\times 100 \% .
\end{gathered}
$$

Moreover, the sensitivity, specificity, positive predictive value (PPV), and negative predictive value (NPV) of machine learning algorithms in each lactation week were also presented (Wong and Lim, 2011). Based on preliminary analysis, Random Forest performed well not only in mode accuracy but also in sensitivity and NPV. The importance of each feature in Random Forest was investigated by mean decreased Gini (Louppe et al., 2013). Briefly, the importance of feature $X_{m}$ to predict $Y$ is evaluated by adding up weighted impurity decreases $p(t) \Delta i\left(s_{t}, t\right)$ for all nodes $t$ where $X_{m}$ is used, averaged over all $N_{T}$ trees in Random Forest:

$$
\operatorname{Imp}\left(X_{m}\right)=\frac{1}{N_{T}} \sum_{T} \sum_{t \in T: v\left(s_{t}\right)=X_{m}} p(t) \Delta i\left(s_{t}, t\right),
$$

where $X_{m}$ is the features used in Random Forest, $p(t)$ is the proportion $N_{t} / N$ of samples reaching $t$, and $v\left(s_{t}\right)$ is the variable used in split $s_{t}$ (Breiman, 2001). A lower Gini (i.e., higher decreased Gini) means that a feature plays a relatively more important role than others to discriminate samples into defined classes.

\section{Data Processing and Software}

Multiple comparison analysis was applied with Tukey's honest significant difference test. Data preprocessing and machine learning algorithms were programmed in the $\mathrm{R}$ environment (version 3.4.3; https: //www.r-project.org/), with function "kmeans()" for cluster analysis, function "prcomp()" for PCA, function "cor.test()" for Pearson analysis, package "rpart" for Decision Tree, "neuralnet" for Bayesian Network, "e1071" for Naïve Bayes and Support Vector Machine, "adabag" for Bootstrap Aggregation, and "randomforest" for Random Forest. Figures were plotted in Python (version 3.6; https://www.python.org/) using modules "pandas," "matplotlib," and "Seaborn."

\section{RESULTS}

\section{PCA and Correlation Analysis}

All plasma metabolites and metabolic hormones were correlated (Pearson) with a correlation coefficient (absolute value $)<0.61(P<0.05)$ or insignificant $(P$ $>0.05$; Table 2). Figure 1 shows the bi-plot (limited to the first 2 components for the sake of simplicity) from the PCA and presents the explained variation in first PC (range: $47.5-62.6 \%$ during wk 1 to 7 ) and second PC (range: 13.5-18.2\%). Inspection of the PCA loadings shows the relative contribution of 5 plasma 
XU ETAL.

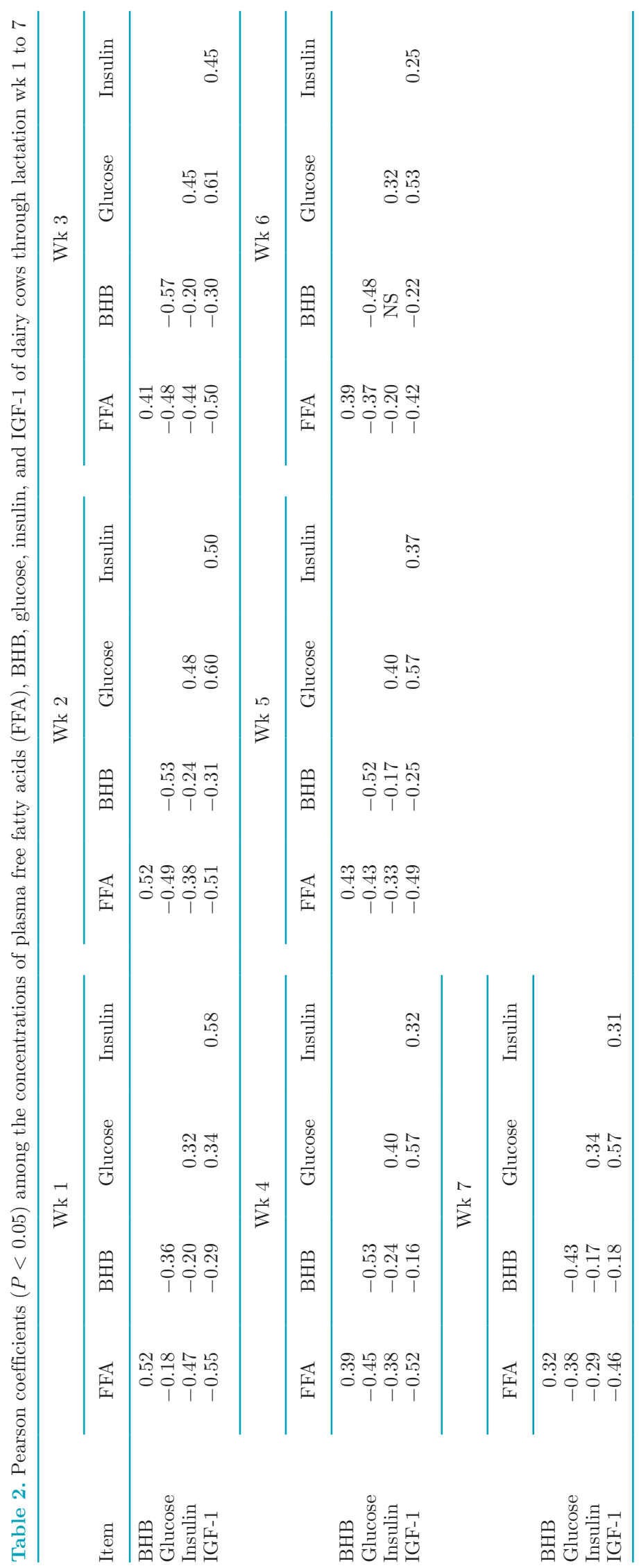


metabolites and hormones to cluster metabolic status of dairy cows (bi-plot of PCA; Figure 1). Raw data of loading are presented in Supplemental Table S1 (https: //doi.org/10.3168/jds.2018-15791). The loading pattern of plasma metabolites and hormones is the same across lactation wk 1 to 7 .

\section{Definition of Clusters for Metabolic Status}

The optimal number of clusters suggested by Average Silhouette was 3 through lactation wk 1 to 7 . In each lactation week, the silhouette widths per $k$ numbers in Cluster Analysis are presented in Supplemental Figure
S1 (https://doi.org/10.3168/jds.2018-15791). Based on the concentration of plasma metabolites and metabolic hormones, cows in the first, second, and third clusters were definied as having good, average, and poor metabolic status, respectively. Cluster 3, defined as poor metabolic status, had the greatest plasma BHB and FFA but the lowest glucose, insulin, and IGF-1 $(P<$ 0.05; Table 3). Conversely, cluster 1 , defined as good metabolic status, had the lowest plasma BHB and FFA but the greatest plasma glucose, insulin, and IGF-1 ( $P$ $<0.05$ ). For all lactation weeks, cluster 2 had a lower plasma BHB and lower plasma FFA than cluster $3(P<$ 0.05 ) but also lower plasma insulin, IGF-1, and glucose
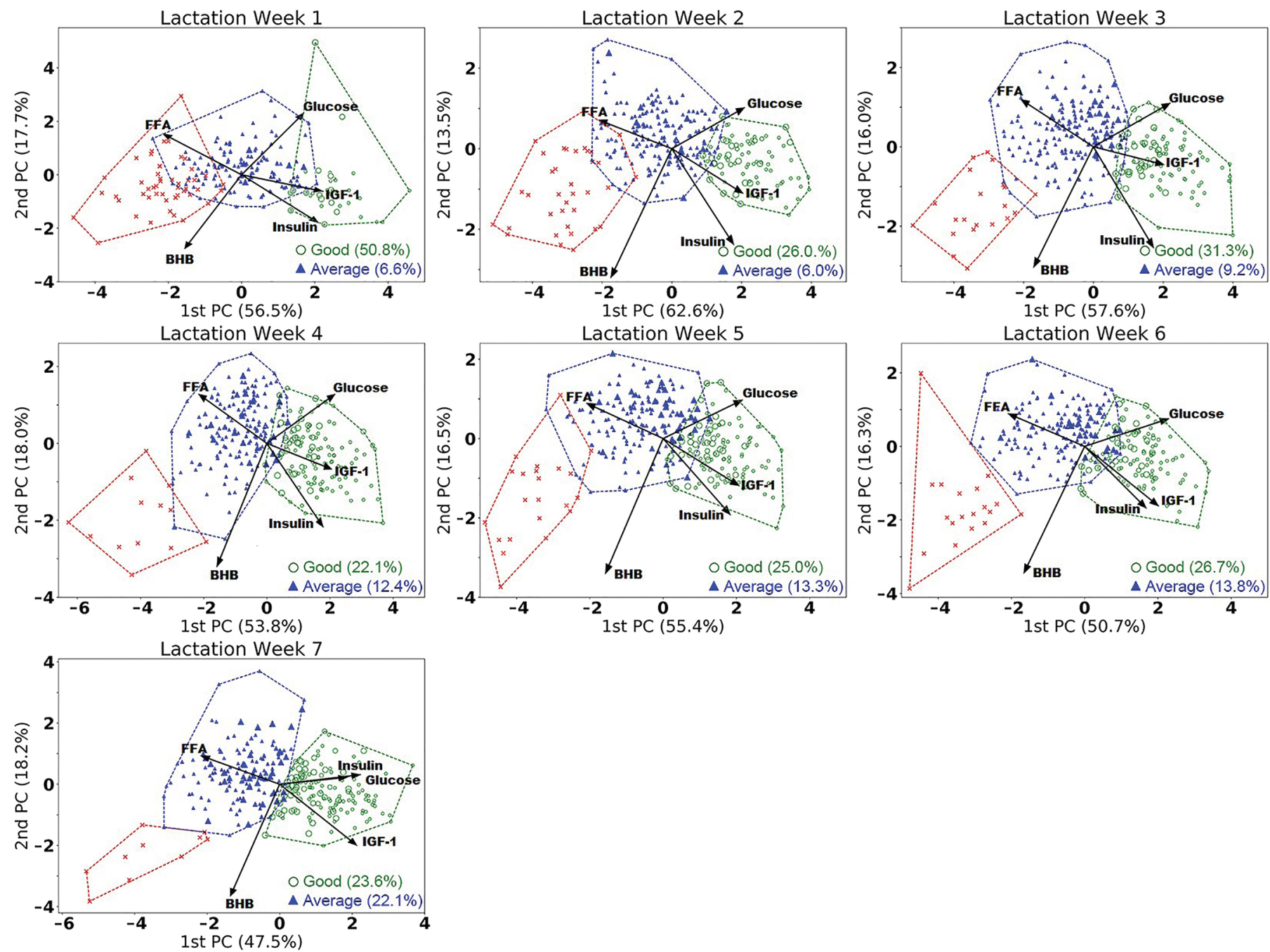

Figure 1. Dairy cows clustered for 3 metabolic clusters through lactation wk 1 to 7 through plasma metabolites and metabolic hormones. Metabolic clusters are defined as good $(O)$, average $(\boldsymbol{\Lambda})$, or poor $(x)$ metabolic status. Percentage in brackets represents error rate to predict cows in good or average metabolic status using on-farm cow data. Error rate of each cow is represented with dot size (small $=$ low error rate; big $=$ high error rate). Cows were plotted as 1 label in a 2-dimensional plot in principal components (PC) analysis; 1st PC and 2nd PC stand for the explained variation by first and second PC in PC analysis, respectively. The arrow line represents the loading of plasma BHB, free fatty acids (FFA), glucose, insulin, and IGF-1 in the first PC in PC analysis through lactation wk 1 to 7. 
Table 3. Plasma metabolite and metabolic hormone concentrations for dairy cows in 3 metabolic clusters in lactation wk 1 to 7 postpartum ${ }^{1}$

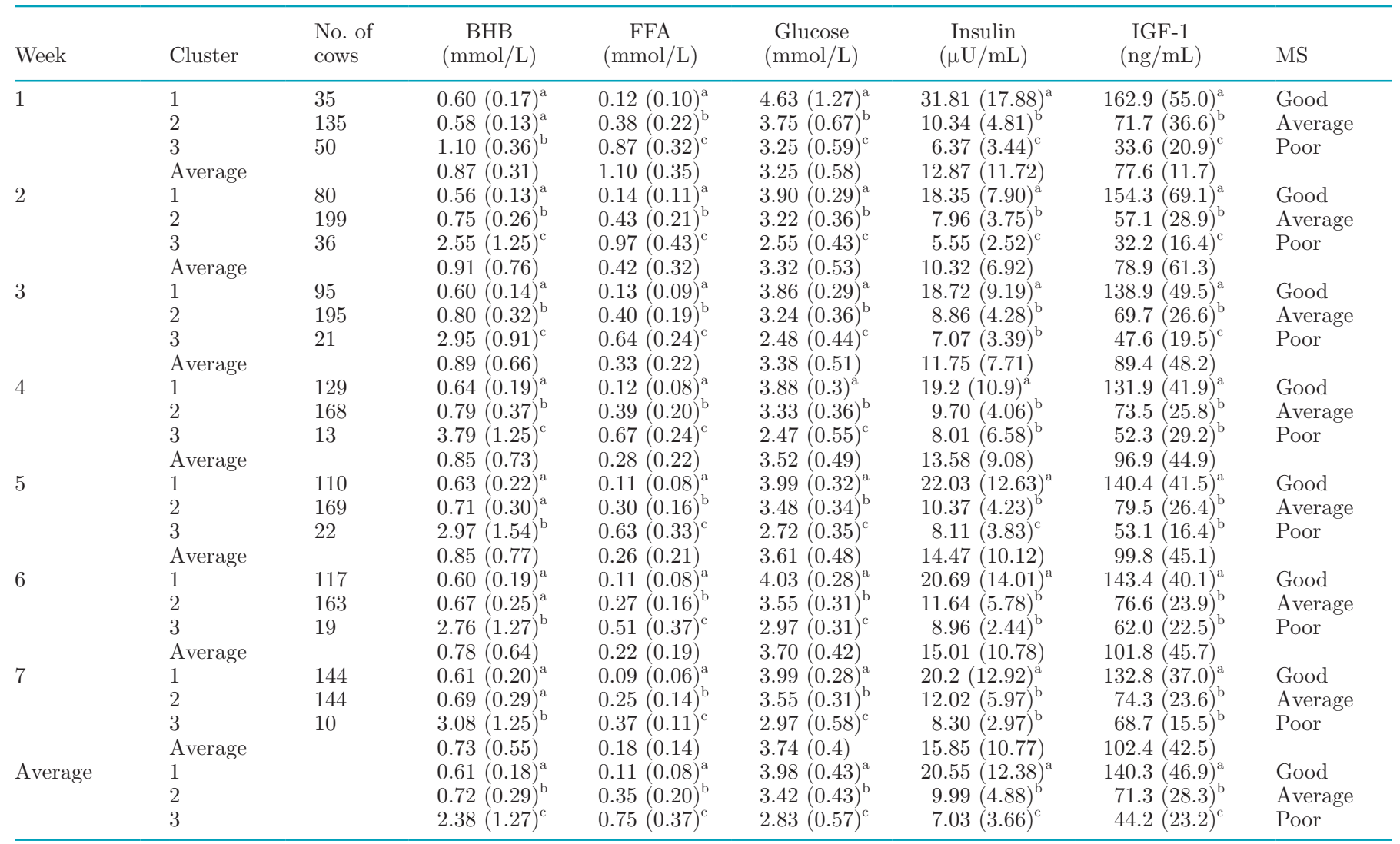

${ }^{\mathrm{a}-\mathrm{c}}$ Values within a lactation week of dairy cows in different metabolic status with different superscripts differ $(P<0.05)$.

${ }^{1}$ Cluster analysis of metabolic status (MS) was based on the concentration of plasma free fatty acids (FFA), BHB, glucose, insulin, and IGF-1.

Values represent means (SD in parentheses).

than cluster $1(P<0.05)$ and was therefore defined as the cluster of cows with an average metabolic status.

\section{Predictive Performance of Machine Learning Algorithms}

To predict cows in either good or average metabolic status, SVM had the lowest error rate in lactation wk 3 to 7 of all algorithms. Random Forest had the lowest error rate in lactation wk 1 and 2 and a slightly higher error rate through lactation wk 3 to 7 (Table 3 ). The sensitivity and NPV of all algorithms were lower in lactation wk 1 than in other weeks. Random Forest had higher sensitivity (range: 67.8-82.9\% during wk 1 to 7 ) and NPV (range: 89.5-93.8\%), and SVM had higher specificity (range: 80.9-93.7\%) and PPV (range: 78.8-86.1\%; Figure 2). After 500 repetitions in Random Forest, error rate to predict cows in good metabolic status was higher than error rate to predict cows in average metabolic status (Figure 1). In 2-dimensional PCA plots, major incorrectly predicted dots (big dots) are mainly presented in the border area between good and average metabolic status groups (Figure 1).

Machine learning algorithms to predict cows in poor, average, or good metabolic status were evaluated (Supplemental Table S2, https://doi.org/10.3168/jds.2018 -15791). The general performance of 8 algorithms decreased when 3 metabolic statuses were included in the prediction compared with 2 metabolic statuses; error rate ranged from 21.36 to $48.7 \%$. Random Forest and SVM were still the best-performing algorithms through all lactation weeks.

\section{Feature Contribution}

Random Forest had a lower error rate but also had the highest sensitivity and NPV to predict dairy cows with good metabolic status (Table 4; Figure 2). The contribution of features to predict metabolic status in Random Forest is shown in Figure 3. Through lactation wk 1 to 3 , milk yield, fat yield, and protein percentage were more important than other features; in wk 4 and 


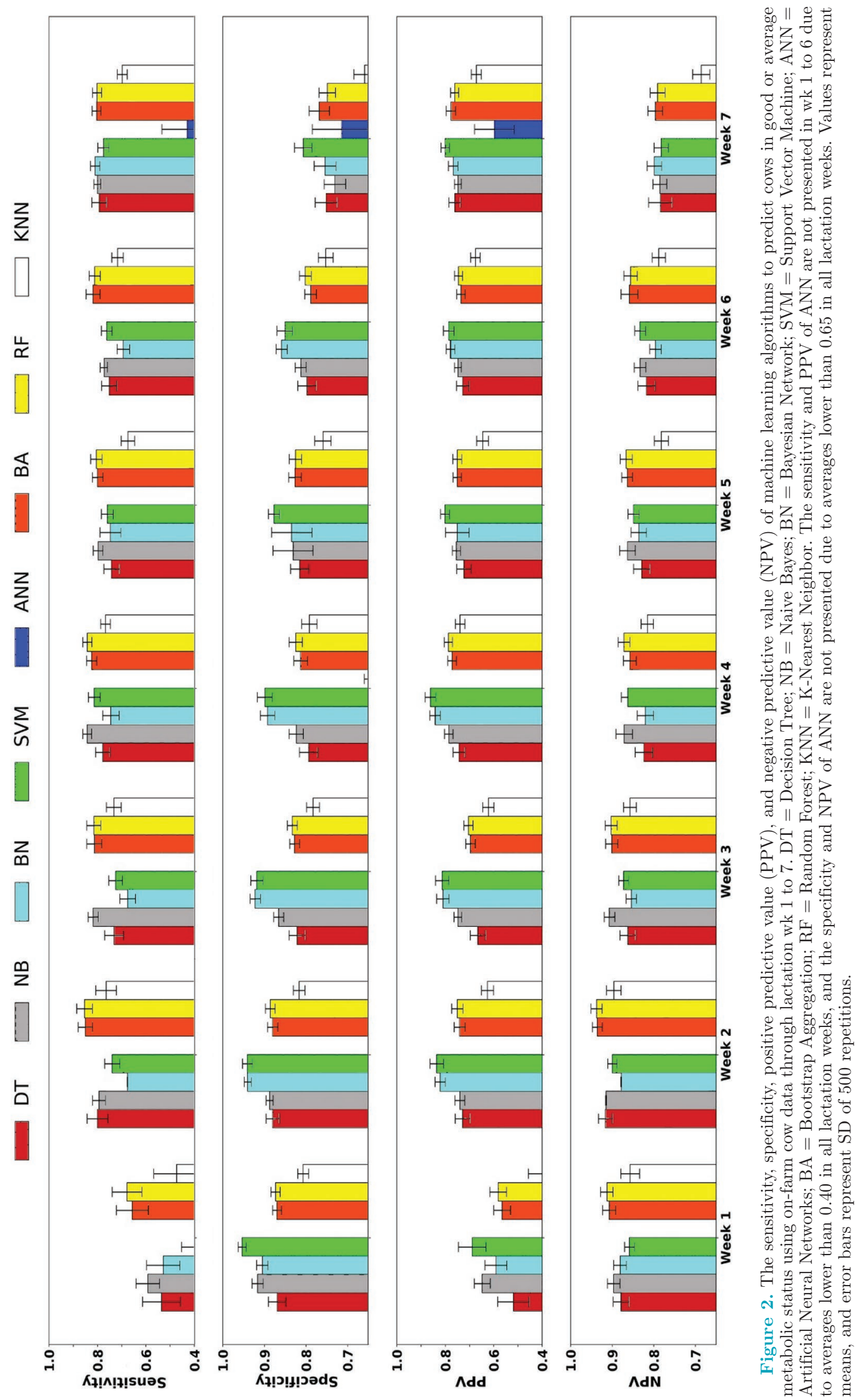


Table 4. Error rate (\%; SD in parentheses) of machine learning algorithms to predict 2 metabolic statuses (good and average) of dairy cows through lactation wk 1 to 7

\begin{tabular}{|c|c|c|c|c|c|c|c|c|}
\hline $\begin{array}{l}\text { Machine learning } \\
\text { algorithm }\end{array}$ & \multicolumn{7}{|c|}{ Lactation week } & Average \\
\hline Bayesian Network & $17.4(1.5)$ & $13.9(1.6)$ & $16.8(1.3)$ & $17.5(1.6)$ & $20.3(1.9)$ & $21.5(1.3)$ & $21.7(1.5)$ & $19.2(2.5)$ \\
\hline Support Vector Machine & $16.4(1.2)$ & $12.4(1.3)$ & $15.4(1.3)$ & $14.1(1.4)$ & $17.3(1.2)$ & $19.0(1.3)$ & $21.1(1.3)$ & $16.5(3.0)$ \\
\hline Artificial Neural Networks & $24.7(2.2)$ & $36.8(2.7)$ & $43.7(3.0)$ & $49.8(5.0)$ & $44.8(3.8)$ & $47.1(4.1)$ & $47.8(6.3)$ & $43.3(7.7)$ \\
\hline K-Nearest Neighbor & $22.3(1.7)$ & $19.8(1.6)$ & $23.4(1.7)$ & $22.1(1.6)$ & $27.9(1.9)$ & $26.4(1.6)$ & $32.3(2.0)$ & $24.9(4.3)$ \\
\hline Average & $18.2(3.0)$ & $15.1(4.8)$ & $18.8(5.0)$ & $18.5(4.3)$ & $23.5(8.9)$ & $24.6(9.0)$ & $24.2(5.3)$ & \\
\hline
\end{tabular}

5 , protein percentage and lactose yield were the most important features to predict metabolic status; and in wk 6 and 7 , milk yield, protein percentage, and lactose yield were more important than other features, whereas fat-related features were not as important as in lactation wk 1 to 3 .

\section{DISCUSSION}

\section{Metabolic Clusters}

In the current study, we first aimed to define metabolic status of dairy cows through cluster analysis based on their plasma metabolites and metabolic hormones through lactation wk 1 to 7 . It was hypothesized that altered plasma metabolites and metabolic hormones between different clusters could indicate the difference in metabolic status. Moreover, the correlation among these plasma variables was in line with previous studies; for example, greater plasma glucose concentration was negatively correlated with plasma BHB and FFA concentration (Francisco et al., 2002; van Knegsel et al., 2007). In the current study, however, the majority of the correlations between plasma metabolites and metabolic hormones had a trend to get weak from lactation wk 1 to 7 . For example, the correlations beween plasma FFA and insulin and between plasma IGF-1 and insulin got smaller from wk 1 until 7. Cluster analysis can be affected by variables with high correlation (Hair et al., 2006), which is usually defined as a correlation of above 0.8 or 0.9 (Franke, 2010). The maximum correlation among variables in the current study was 0.61 . An alternative could be to perform cluster analysis on selected PC, which are orthogonal and thus uncorrelated (Borcard et al., 2011; Tremblay et al., 2018). The sum explained variation by first and second PC accounted for 65.7 to $76.1 \%$ over lactation weeks in the current study (Figure 1). Therefore, when using selected PC (e.g., 2 PC) from PCA in cluster analysis, 2 PC could account for only 65.7 to $76.1 \%$ of explained variation of 5 plasma metabolites and metabolic hormones.

In the current study, metabolic status was a composite trait of plasma BHB, FFA, glucose, insulin, and IGF-1. Cows with poor metabolic status had, on average, a greater BHB concentration than the earlier suggested threshold for subclinical ketosis $(>1.2 \mathrm{mmol} / \mathrm{L}$; Duffield and LeBlanc, 2009), or a greater plasma FFA than the suggested threshold for subclinical ketosis (>0.6 mmol/L; Seifi et al., 2011), except in lactation wk 7. Recently, Tremblay et al. (2018) identified plasma values for poor metabolic adaptation syndrome (PMAS) in dairy cows in early lactation. Results of this study are in line with the current study for cows with good metabolic status but not completely for cows with poor metabolic status. In the current study, cows with good metabolic status had, on average, a lower plasma FFA concentration over lactation weeks than the earlier suggested threshold for low PMAS $(<0.39$ mmol/L; Tremblay et al., 2018). However, cows with poor metabolic status had, on average, a greater plasma FFA concentration in wk 1 and 2 than the earlier suggested threshold for high PMAS $(\geq 0.7 \mathrm{mmol} / \mathrm{L}$; Tremblay et al., 2018). The difference between these 2 studies might be related to the fact that PMAS clusters were based on plasma FFA, BHB, and milk fat: protein ratio (Tremblay et al., 2018), whereas in the current study metabolic status was a composite trait based on plasma FFA, BHB, glucose, insulin, and IGF1. For all lactation weeks, cows with good metabolic status had plasma IGF-1 concentration $>100 \mathrm{ng} / \mathrm{mL}$ (Lomander et al., 2012) and greater plasma glucose and insulin concentration compared with the other 2 clusters. Moreover, in our study, cluster analysis was done per lactation week, which avoids a possible confounding effect of lactation stage with metabolic status of dairy cows. The implication of this approach is that metabolic health classifications are relative to the other 2 clusters within a lactation week. This could imply 

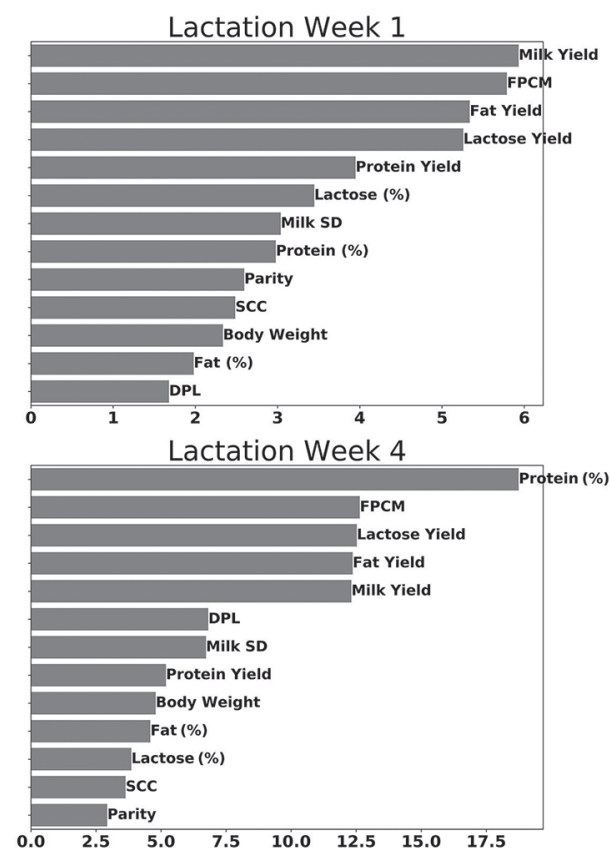

Lactation Week 7

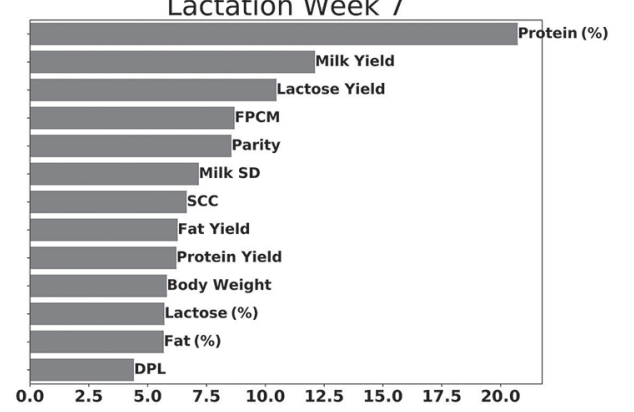

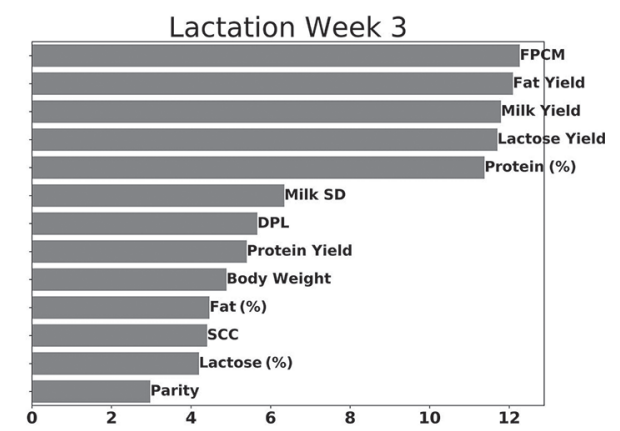
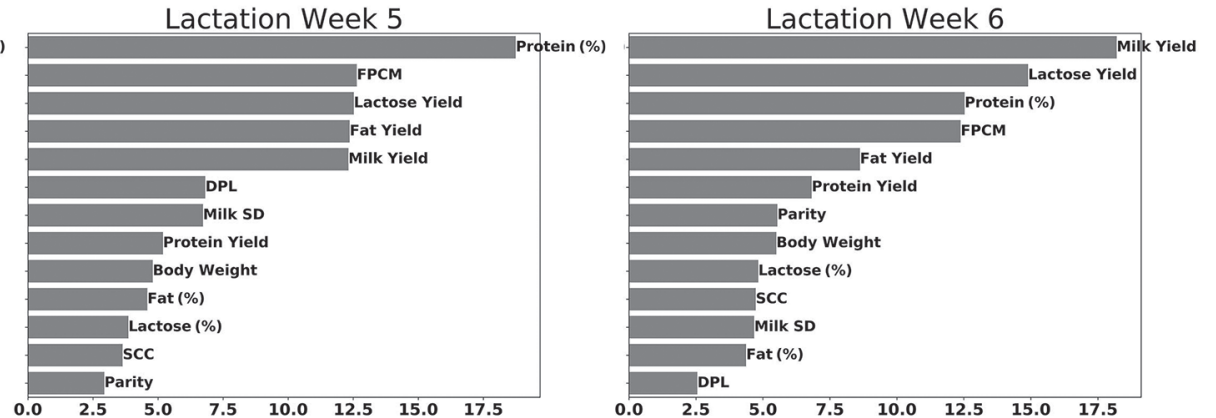

Figure 3. Importance of all features in Random Forest classification through lactation wk 1 to 7 . Contribution of features was evaluated by Mean Decreased Gini (Equation 2). DPL = dry period length; FPCM = fat- and protein-corrected milk production; Milk SD = standard deviation of daily milk yield. X-axis represents mean decreased Gini of each variable.

that what was definied as poor metabolic status in wk 2 is different from what was definied as poor metabolic status in wk 7. However, comparing clusters 1 and 3 over lactation weeks shows that the differences over lactation weeks among clusters are marginal, indicating that the cows definied as having a poor metabolic status have a similar metabolic profile over the first 7 lactation weeks in the current study.

In a bi-plot of PCA, the opposing loadings of 5 plasma metabolites and metabolic hormones could indicate how these values contribute to the separation of dairy cows into good, average, or poor metabolic status. The negative contribution of plasma $\mathrm{BHB}$ and FFA to the first PC means that high $\mathrm{BHB}$ and FFA are related to poor metabolic status in cluster analysis. Concentration of FFA is an indicator of fat mobilization during poor metabolic status, whereas plasma BHB is an indicator of fat metabolism and incomplete oxidation of fat (Grummer, 1993). In our study, cows with poor metabolic status had the lowest concentration of glucose, insulin, and IGF-1 among 3 clusters. Glucose in early lactation is essential not only for lactose production but also for metabolizing fatty acids and making energy available to the body in the form of ATP (van Knegsel et al., 2005). Low insulin reduces glucose uptake by insulinresponsive peripheral tissues (adipose and muscle) and facilitates greater uptake of glucose by the mammary gland (Bauman and Elliot, 1983). Low concentration of IGF-1 and insulin is related to the negative energy balance status of cows (Lucy et al., 1992). Cows with the greatest concentration of insulin and IGF-1 were defined as having a good metabolic status, which fits with the observation that great concentrations of insulin and IGF-1 were found in cows with positive energy balance 
(Lucy et al., 1992; McGuire et al., 1995). Associated with increasing plasma glucose and insulin availability, increased IGF-1 can be hypothesized to have anabolic effects on carbohydrate metabolism (Harding et al., 1994; Rigout et al., 2002). Cows with good metabolic status had greater IGF-1 (Table 2), lower BW, and lower average parity (Supplemental Table S3, https:/ /doi.org/10.3168/jds.2018-15791). In mammals, IGF-1 promotes growth and aging (Gems and Partridge, 2001; Sonntag et al., 2005), which could indicate that cows in good metabolic status have a more anabolic status. Therefore, cows in good metabolic status have low BW, milk yield, protein yield, and fat yield (Supplemental Table S3, https://doi.org/10.3168/jds.2018-15791). The low average BW and low average parity in this cluster suggest that there might be a greater proportion of young cows that still have some priority for growth in this cluster, which might explain the greater plasma IGF-1 concentration for these cows.

In the current study, machine learning algorithms were used to predict cows in good or average metabolic status but not cows in poor metabolic status. This approach was chosen due to a limited number of animals in the cluster with a poor metabolic status to improve the predictive performance of the algorithms. For cow health management, however, prediction of cows in poor metabolic status is very informative. Therefore, evaluation of machine learning algorithms to predict cows in poor, average, or good metabolic status is included in Supplemental Table S2 (https://doi.org/10.3168/jds .2018-15791). Identification of metabolic status could facilitate cow health management by fine-tuning dietary and management strategies for individual dairy cows in a precision farming system (as reviewed by Rutten et al., 2013). On the one hand, cows in poor metabolic status could be supplied with a diet with greater energy content or assigned to a $30-$ or $0-\mathrm{d}$ DP to improve metabolic status in the next lactation. On the other hand, cows in good metabolic status might deserve extra attention to prevent metabolic diseases in the next lactation caused by body fat accumulation in the current lactation (Grummer, 1993). First, limiting energy supply could result in reduced body fat storage and lower BCS (Dewhurst et al., 2000). Second, cows with good metabolic status are candidates for a 30- or 60-d DP to reduce energy balance and maximize milk yield in the next lactation (Chen et al., 2016).

\section{Predicting Metabolic Status with Machine Learning Algorithms}

In this study, $k$-means was an unsupervised learning method in cluster analysis, whereas K-Nearest Neigh- bor was a supervised learning method to predict metabolic status. Although both algorithms used Euclidean distance as kernel function, K-Nearest Neighbor could limitedly predict metabolic status with on-farm cow data. It is difficult to consider a specific linear function with conventional statistical methods due to its limitations when using correlated variables. In this context, analyzing data through machine learning algorithms seems promising to manage large data sets with onfarm cow data with a lot of correlations among features (Caraviello et al., 2006).

The superior performance of Random Forest and Bootstrap Aggregation is in line with a study that predicts insemination outcomes in cows (Shahinfar et al., 2014), which could be explained by the power of ensemble methods to generate high-performance classifiers by collecting individual trained classifiers. Although Random Forest performed better than the other algorithms, even to predict cows with 3 metabolic statuses in our study (Supplemental Table S2, https:// doi.org/10.3168/jds.2018-15791), it does not mean that Random Forest will always be the best algorithm in practice. The performance of all algorithms (e.g., Random Forest) depends on used features and parameters. A multiparallel comparison among algorithms, therefore, is necessary to evaluate algorithms in a specific case.

Other machine learning algorithms had a relatively higher error rate than Random Forest and Bootstrap Aggregation. Among all algorithms, ANN is frequently used, for example, to predict milk yield (Grzesiak et al., 2006; Gianola et al., 2011) and classify mastitis cases (Cavero et al., 2008; Sun et al., 2010). In our study, however, the error rate of ANN (21.3-39.2\%; Table 3) in prediction of metabolic status is high compared with other studied algorithms. The reasons for difference in fit of ANN among studies are unknown.

All algorithms had a better prediction of metabolic status of cows in lactation wk 2 and 3 compared with prediction in wk 1 and 4 to 7 , which could be explained by the dramatic changes of metabolic status at the beginning of lactation (Drackley, 1999). Dramatic changes of metabolic status in cows with low adaptive capacity in early lactation could benefit the prediction of metabolic status by machine learning algorithm in the current study. In addition, major incorrectly predicted cases in Random Forest were presented in the border area between good and average metabolic status of cows in the PCA plot (Figure 1). This result indicates that on-farm cow data are limited to predict metabolic status of cows in the border area between clusters, which could be explained by some features that are not different between cows in good or average metabolic 
status, such as BW, fat percentage, lactose percentage, and FPCM (Supplemental Table S3, https://doi.org/10 .3168/jds.2018-15791).

The performance of algorithms with different sensitivity, specificity, PPV, and NPV determines application in practice. The relative higher sensitivity and NPV value of Random Forest could be helpful to detect cows with surplus energy balance (also referred to good metabolic status). It would be expected to further study the reason why machine learning algorithms perform differently in sensitivity, specificity, PPV, and NPV and improve the performance of applied algorithms in practice (e.g., how the sensitivity of prediction of metabolic status could be improved using dietary component data). Moreover, several other aspects can be hypothesized to facilitate further fine-tuning of machine learning algorithms to predict metabolic status. First, larger data sets and more comprehensive on-farm cow data or on-farm noncow data (e.g., data sets including more cows in poor metabolic status) would allow more precise prediction of cows in poor metabolic status, and weather data could be used to predict energy intake of dairy cows (West et al., 2003), which could be related to metabolic status in early lactation. Second, in the current study, features were included as the weekly average or standard deviation per week for milk yield. Also, other on-farm cow data can be hypothesized to contribute to a model to estimate metabolic status, such as minimum or maximum milk yield, feeding activity, or lying time per day (van Hoeij et al., 2019). Third, models could be further optimized using not only data per lactation week but also data of all lactation weeks at once. This would imply that the random effect of individual cows in consecutive lactation weeks needs to be considered, which would request more complicated algorithms, which are, to our knowledge, not standard procedure. Fourth, machine learning algorithms can be used to predict not only metabolic status, as in Tremblay et al. (2018) or the current study, but specific diseases and disorders associated with metabolic status, such as fatty liver or subclinical ketosis in dairy cows (Pralle et al., 2018).

\section{Important Features}

In the current study, Random Forest had the relative lower error rate but also had the highest sensitivity and NPV to predict 362 dairy cows with good metabolic status. In lactation wk 1, 2, and 3, milk yield, fat yield, and protein percentage played important roles in predicting cows in good or average metabolic status in Random Forest, which could be explained by relation between milk production and body fat mobilization. Increased fat yield in early lactation originates partly from mobilized body fat; this process is related to elevated plasma concentration of FFA and BHB (Grummer, 1993). Therefore, milk fat and fat:protein ratio were used to estimate energy balance of cows at the herd level (Friggens et al., 2007; Buttchereit et al., 2010). In the current study, in lactation wk 4 and 5 , protein percentage and lactose yield were the top 2 important features in Random Forest. It can be speculated that milk protein and lactose are important to assign cows to good or average metabolic status. Cows in average metabolic status had greater protein and lactose production than cows in good and poor metabolic status (Supplemental Table S3, https://doi.org/10.3168/jds.2018-15791). In lactation wk 6 and 7, fat-related features were not as important as milk yield, milk protein percentage, and lactose yield. In lactation wk 6 and 7 , cows in average metabolic status had the same fat yield as cows in poor metabolic status (Supplemental Table S3, https://doi .org/10.3168/jds.2018-15791), which could be explained by the recovery to positive energy balance status after 41.5 DIM postpartum (de Vries and Veerkamp, 2000). Fine-tuning the model by adjusting the contribution of milk yield, fat yield, protein percentage, and lactose yield in each lactation week to the model could improve predictive performance in further studies.

\section{CONCLUSIONS}

Through lactation wk 1 to 7 , dairy cows were clustered by poor, average, or good metabolic status based on 5 plasma metabolites and metabolic hormones. Onfarm cow data predicted cows in good or average metabolic status in early lactation using 8 machine learning algorithms. Error rate of those algorithms ranged from 12.4 to $49.8 \%$. Of all algorithms, Random Forest and SVM had stable and best performance to predict metabolic status of dairy cows. Milk yield, fat yield, protein percentage, and lactose yield had important roles in Random Forest; however, their rank of importance differed across lactation weeks.

\section{ACKNOWLEDGMENTS}

The authors thank the Chinese Scholarship Council for financial support of the PhD study of the first author. The authors thank the staff of Dairy Campus (Lelystad, the Netherlands) and Gerrit Remmelink (Wageningen Livestock Research, Lelystad, the Netherlands) for their assistance during the experiment. 


\section{REFERENCES}

Bauman, D., and J. Elliot. 1983. Control of nutrient partitioning in lactating ruminants. Pages 437-462 in Biochemistry of Lactation. T. B. Mepham, ed. Elsevier, Amsterdam, the Netherlands.

Bell, A. W. 1995. Regulation of organic nutrient metabolism during transition from late pregnancy to early lactation. J. Anim. Sci. 73:2804-2819. https://doi.org/10.2527/1995.7392804x.

Bernabucci, U., B. Ronchi, N. Lacetera, and A. Nardone. 2005. Influence of body condition score on relationships between metabolic status and oxidative stress in periparturient dairy cows. J. Dairy Sci. 88:2017-2026. https://doi.org/10.3168/jds.S0022 $-0302(05) 72878-2$.

Borcard, D., F. Gillet, and P. Legendre. 2011. Numerical Ecology. R. Springer, New York, NY.

Breiman, L. 1996a. Bagging predictors. Mach. Learn. 24:123-140. https://doi.org/10.1007/BF00058655.

Breiman, L. 1996b. Out-of-Bag Estimation. University of California, Berkeley.

Breiman, L. 2001. Random forests. Mach. Learn. 45:5-32. https://doi .org/10.1023/A:1010933404324

Butler, W. R. 2003. Energy balance relationships with follicular development, ovulation and fertility in postpartum dairy cows. Livest. Prod. Sci. 83:211-218. https://doi.org/10.1016/S0301 -6226(03)00112-X.

Buttchereit, N., E. Stamer, W. Junge, and G. Thaller. 2010. Evaluation of five lactation curve models fitted for fat:protein ratio of milk and daily energy balance. J. Dairy Sci. 93:1702-1712. https:/ /doi.org/10.3168/jds.2009-2198.

Caraviello, D. Z., K. Weigel, M. Craven, D. Gianola, N. Cook, K. Nordlund, P. Fricke, and M. Wiltbank. 2006. Analysis of reproductive performance of lactating cows on large dairy farms using machine learning algorithms. J. Dairy Sci. 89:4703-4722. https://doi.org/ 10.3168/jds.S0022-0302(06)72521-8.

Cavero, D., K.-H. Tölle, C. Henze, C. Buxadé, and J. Krieter. 2008. Mastitis detection in dairy cows by application of neural networks. Livest. Sci. 114:280-286. https://doi.org/10.1016/j.livsci.2007.05 012 .

Chen, J., G. J. Remmelink, J. J. Gross, R. M. Bruckmaier, B. Kemp, and A. T. M. van Knegsel. 2016. Effects of dry period length and dietary energy source on milk yield, energy balance, and metabolic status of dairy cows over 2 consecutive years: Effects in the second year. J. Dairy Sci. 99:4826-4838. https://doi.org/10.3168/jds.2015 -10742 .

CVB (Centraal Veevoeder Bureau). 2011. Chemische samenstellingen en nutritionele waarden van voedermiddelen [in Dutch]. Productschap Diervoeder, CBV, The Hague, the Netherlands.

Dann, H. M., D. Morin, G. Bollero, M. Murphy, and J. Drackley. 2005. Prepartum intake, postpartum induction of ketosis, and periparturient disorders affect the metabolic status of dairy cows. J. Dairy Sci. 88:3249-3264. https://doi.org/10.3168/jds.S0022 -0302(05)73008-3.

de Feu, M. A., A. Evans, P. Lonergan, and S. T. Butler. 2009. The effect of dry period duration and dietary energy density on milk production, bioenergetic status, and postpartum ovarian function in Holstein-Friesian dairy cows. J. Dairy Sci. 92:6011-6022. https: //doi.org/10.3168/jds.2009-2374.

de Vries, M. J., and R. F. Veerkamp. 2000. Energy balance of dairy cattle in relation to milk production variables and fertility. J. Dairy Sci. 83:62-69. https://doi.org/10.3168/jds.S0022-0302(00)74856-9.

Dewhurst, R. J., J. Moorby, M. Dhanoa, R. Evans, and W. Fisher. 2000. Effects of altering energy and protein supply to dairy cows during the dry period. 1. Intake, body condition, and milk production. J. Dairy Sci. 83:1782-1794. https://doi.org/10.3168/jds S0022-0302(00)75049-1.

Domingos, P., and M. Pazzani. 1997. On the optimality of the simple Bayesian classifier under zero-one loss. Mach. Learn. 29:103-130. https://doi.org/10.1023/A:1007413511.

Dormann, C. F., J. Elith, S. Bacher, C. Buchmann, G. Carl, G. Carré, J. R. G. Marquéz, B. Gruber, B. Lafourcade, and P. J. Leitão.
2013. Collinearity: A review of methods to deal with it and a simulation study evaluating their performance. Ecography 36:27-46. https://doi.org/10.1111/j.1600-0587.2012.07348.x.

Drackley, J. K. 1999. Biology of dairy cows during the transition period: The final frontier? J. Dairy Sci. 82:2259-2273. https://doi .org/10.3168/jds.S0022-0302(99)75474-3.

Duffield, T., and S. LeBlanc. 2009. Interpretation of serum metabolic parameters around the transition period. Pages 106-114 in Proc. Southwest Nutrition and Management Conference, Tempe, AZ

Francisco, C. C., C. Chamberlain, D. Waldner, R. Wettemann, and L. Spicer. 2002. Propionibacteria fed to dairy cows: Effects on energy balance, plasma metabolites and hormones, and reproduction. J. Dairy Sci. 85:1738-1751. https://doi.org/10.3168/jds .S0022-0302(02)74248-3.

Franke, G. R. 2010. Multicollinearity. Pages 197-198 in Wiley International Encyclopedia of Marketing. Jagdish N. Sheth and Naresh K. Malhotra, ed. John Wiley \& Sons Ltd., Hoboken, NJ.

Friggens, N. C., C. Ridder, and P. Løvendahl. 2007. On the use of milk composition measures to predict the energy balance of dairy cows. J. Dairy Sci. 90:5453-5467. https://doi.org/10.3168/jds.2006-821.

Gems, D., and L. Partridge. 2001. Insulin/IGF signalling and ageing: Seeing the bigger picture. Curr. Opin. Genet. Dev. 11:287-292. https://doi.org/10.1016/S0959-437X(00)00192-1.

Gianola, D., H. Okut, K. A. Weigel, and G. J. Rosa. 2011. Predicting complex quantitative traits with Bayesian neural networks: A case study with Jersey cows and wheat. BMC Genet. 12:87. https://doi .org/10.1186/1471-2156-12-87.

Graber, M., S. Kohler, A. Müller, K. Burgermeister, T. Kaufmann, R. Bruckmaier, and H. van Dorland. 2012. Identification of plasma and hepatic parameters related to metabolic robustness in dairy cows. J. Anim. Physiol. Anim. Nutr. (Berl.) 96:75-84. https://doi .org/10.1111/j.1439-0396.2010.01124.x.

Grummer, R. R. 1993. Etiology of lipid-related metabolic disorders in periparturient dairy cows. J. Dairy Sci. 76:3882-3896. https://doi .org/10.3168/jds.S0022-0302(93)77729-2.

Grzesiak, W., P. Błaszczyk, and R. Lacroix. 2006. Methods of predicting milk yield in dairy cows - Predictive capabilities of Wood's lactation curve and artificial neural networks (ANNs). Comput. Electron. Agric. 54:69-83. https://doi.org/10.1016/j.compag.2006 .08 .004 .

Hair, J. F., W. C. Black, B. J. Babin, R. E. Anderson, and R. L. Tatham. 2006. Multivariate Data Analysis. 6th ed. Prentice Hall, Upper Saddle River, NJ.

Hall, M. A. 1999. Correlation-Based Feature Selection for Machine Learning. PhD Thesis. The University of Waikato, Hamilton, New Zealand.

Harding, J. E., L. Liu, P. Evans, and P. Gluckman. 1994. Insulin-like growth factor 1 alters feto-placental protein and carbohydrate metabolism in fetal sheep. Endocrinology 134:1509-1514. https://doi .org/10.1210/endo.134.3.8119193.

Hempstalk, K., S. McParland, and D. Berry. 2015. Machine learning algorithms for the prediction of conception success to a given insemination in lactating dairy cows. J. Dairy Sci. 98:5262-5273. https://doi.org/10.3168/jds.2014-8984.

Hostens, M., J. Ehrlich, B. Van Ranst, and G. Opsomer. 2012. Onfarm evaluation of the effect of metabolic diseases on the shape of the lactation curve in dairy cows through the MilkBot lactation model. J. Dairy Sci. 95:2988-3007. https://doi.org/10.3168/ jds.2011-4791.

Hsu, C. W., C. C. Chang, and C. J. Lin. 2003. A Practical Guide to Support Vector Classification. National Taiwan University, Taipei

Hu, L. Y., M. W. Huang, S. W. Ke, and C. F. Tsai. 2016. The distance function effect on k-nearest neighbor classification for medical datasets. Springerplus 5:1304. https://doi.org/10.1186/s40064 $-016-2941-7$

Ingvartsen, K. L., and J. B. Andersen. 2000. Integration of metabolism and intake regulation: A review focusing on periparturient animals. J. Dairy Sci. 83:1573-1597. https://doi.org/10.3168/jds .S0022-0302(00)75029-6. 
Ingvartsen, K. L., R. Dewhurst, and N. Friggens. 2003. On the relationship between lactational performance and health: Is it yield or metabolic imbalance that cause production diseases in dairy cattle? A position paper. Livest. Prod. Sci. 83:277-308. https:// doi.org/10.1016/S0301-6226(03)00110-6.

ISO (International Organization for Standardization). 2013. Milk and liquid milk products - Guidelines for the application of mid-infrared spectrometry. Standard no. 9622:2013. International Organization of Standardization, Geneva, Switzerland.

Johnson, R. A., and D. W. Wichern. 2002. Applied Multivariate Statistical Analysis. 5th ed. Prentice-Hall International, Upper Saddle River, NJ.

Liaw, A., and M. Wiener. 2002. Classification and regression by randomForest. R News 2:18-22.

Liechty, J. C., M. W. Liechty, and P. Müller. 2004. Bayesian correlation estimation. Biometrika 91:1-14. https://doi.org/10.1093/ biomet/91.1.1.

Lomander, H., J. Frössling, K. L. Ingvartsen, H. Gustafsson, and C. Svensson. 2012. Supplemental feeding with glycerol or propylene glycol of dairy cows in early lactation - Effects on metabolic status, body condition, and milk yield. J. Dairy Sci. 95:2397-2408. https://doi.org/10.3168/jds.2011-4535.

Louppe, G., L. Wehenkel, A. Sutera, and P. Geurts. 2013. Understanding variable importances in forests of randomized trees. Pages 431-439 in Proc. 27th Annual Conference on Neural Information Processing Systems, Lake Tahoe, NV. Curran Associates Inc., Red Hook, NY.

Løvendahl, P., C. Ridder, and N. C. Friggens. 2010. Limits to prediction of energy balance from milk composition measures at individual cow level. J. Dairy Sci. 93:1998-2006. https://doi.org/10 .3168/jds.2009-2739.

Lucy, M., C. Staples, W. Thatcher, P. Erickson, R. Cleale, J. Firkins, J. Clark, M. Murphy, and B. Brodie. 1992. Influence of diet composition, dry-matter intake, milk production and energy balance on time of post-partum ovulation and fertility in dairy cows. Anim. Sci. 54:323-331. https://doi.org/10.1017/S0003356100020778.

McArt, J. A., D. V. Nydam, G. R. Oetzel, T. R. Overton, and P. A. Ospina. 2013. Elevated non-esterified fatty acids and $\beta$-hydroxybutyrate and their association with transition dairy cow performance. Vet. J. 198:560-570.

McGuire, M. A., D. A. Dwyer, R. J. Harrell, and D. E. Bauman. 1995. Insulin regulates circulating insulin-like growth factors and some of their binding proteins in lactating cows. Am. J. Physiol. 269:E723E730. https://doi.org/10.1152/ajpendo.1995.269.4.E723.

$\mathrm{Ng}$, A. Y., and M. I. Jordan. 2001. On discriminative vs. generative classifiers: A comparison of logistic regression and naive bayes. Pages 841-848 in Proc. 14th International Conference on Neural Information Processing Systems: Natural and Synthetic, Vancouver, BC, Canada. MIT Press, Cambridge, MA.

Nielsen, N. I., N. C. Friggens, M. G. Chagunda, and K. L. Ingvartsen. 2005. Predicting risk of ketosis in dairy cows using in-line measurements of $\beta$-hydroxybutyrate: A biological model. J. Dairy Sci. 88:2441-2453. https://doi.org/10.3168/jds.S0022-0302(05)72922 -2 .

Pearl, J. 2014. Markov and Bayesian networks: Two graphical representations of probabilistic knowledge. Pages 77-141 in Probabilistic Reasoning in Intelligent Systems. M. B. Morgan, ed. Morgan Kaufmann, San Francisco, CA.

Pezeshki, A., J. Mehrzad, G. R. Ghorbani, H. R. Rahmani, R. J. Collier, and C. Burvenich. 2007. Effects of short dry periods on performance and metabolic status in Holstein dairy cows. J. Dairy Sci. 90:5531-5541. https://doi.org/10.3168/jds.2007-0359.

Pralle, R. S., K. Weigel, and H. White. 2018. Predicting blood $\beta$-hydroxybutyrate using milk Fourier transform infrared spectrum, milk composition, and producer-reported variables with multiple linear regression, partial least squares regression, and artificial neural network. J. Dairy Sci. 101:4378-4387. https://doi .org/10.3168/jds.2017-14076.

Quinlan, J. R. 1996. Improved use of continuous attributes in C4.5. J. Artif. Intell. Res. 4:77-90. https://doi.org/10.1613/jair.279.
Rigout, S., S. Lemosquet, J. Van Eys, J. Blum, and H. Rulquin. 2002. Duodenal glucose increases glucose fluxes and lactose synthesis in grass silage-fed dairy cows. J. Dairy Sci. 85:595-606. https://doi .org/10.3168/jds.S0022-0302(02)74113-1.

Rousseeuw, P. J. 1987. Silhouettes: A graphical aid to the interpretation and validation of cluster analysis. J. Comput. Appl. Math. 20:53-65. https://doi.org/10.1016/0377-0427(87)90125-7.

Rutten, C. J., A. Velthuis, W. Steeneveld, and H. Hogeveen. 2013. Invited review: Sensors to support health management on dairy farms. J. Dairy Sci. 96:1928-1952.

Seifi, H. A., S. J. LeBlanc, K. E. Leslie, and T. F. Duffield. 2011. Metabolic predictors of post-partum disease and culling risk in dairy cattle. Vet. J. 188:216-220.

Shahinfar, S., H. Mehrabani-Yeganeh, C. Lucas, A. Kalhor, M. Kazemian, and K. A. Weigel. 2012. Prediction of breeding values for dairy cattle using artificial neural networks and neuro-fuzzy systems. Comput. Math. Methods Med. 2012. https://doi.org/10 $.1155 / 2012 / 127130$.

Shahinfar, S., D. Page, J. Guenther, V. Cabrera, P. Fricke, and K. Weigel. 2014. Prediction of insemination outcomes in Holstein dairy cattle using alternative machine learning algorithms. J. Dairy Sci. 97:731-742. https://doi.org/10.3168/jds.2013-6693.

Sonntag, W. E., M. Ramsey, and C. S. Carter. 2005. Growth hormone and insulin-like growth factor-1 (IGF-1) and their influence on cognitive aging. Ageing Res. Rev. 4:195-212. https://doi.org/10 $.1016 /$ j.arr.2005.02.001.

Sun, Z., S. Samarasinghe, and J. Jago. 2010. Detection of mastitis and its stage of progression by automatic milking systems using artificial neural networks. J. Dairy Res. 77:168-175. https://doi.org/10 1017/S0022029909990550.

Tan, S. 2006. An effective refinement strategy for KNN text classifier. Expert Syst. Appl. 30:290-298. https://doi.org/10.1016/j.eswa .2005.07.019.

Tremblay, M., M. Kammer, H. Lange, S. Plattner, C. Baumgartner, J. A. Stegeman, J. Duda, R. Mansfeld, and D. Döpfer. 2018. Identifying poor metabolic adaptation during early lactation in dairy cows using cluster analysis. J. Dairy Sci. 101:7311-7321. https:// doi.org/10.3168/jds.2017-13582.

van Hoeij, R. J., J. Dijkstra, R. M. Bruckmaier, J. J. Gross, T. Lam, G. J. Remmelink, B. Kemp, and A. T. M. van Knegsel. 2017. The effect of dry period length and postpartum level of concentrate on milk production, energy balance, and plasma metabolites of dairy cows across the dry period and in early lactation. J. Dairy Sci. 100:5863-5879. https://doi.org/10.3168/jds.2016-11703.

van Hoeij, R. J., A. Kok, R. M. Bruckmaier, M. J. Haskell, B. Kemp, and A. T. M. van Knegsel. 2019. Relationship between metabolic status and behavior in dairy cows in week 4 of lactation. Animal 13:640-648. https://doi.org/10.1017/S1751731118001842.

van Knegsel, A. T., G. Remmelink, S. Jorjong, V. Fievez, and B. Kemp. 2014. Effect of dry period length and dietary energy source on energy balance, milk yield, and milk composition of dairy cows. J. Dairy Sci. 97:1499-1512. https://doi.org/10.3168/jds.2013-7391.

van Knegsel, A. T., H. Van den Brand, E. Graat, J. Dijkstra, R. Jorritsma, E. Decuypere, S. Tamminga, and B. Kemp. 2007. Dietary energy source in dairy cows in early lactation: Metabolites and metabolic hormones. J. Dairy Sci. 90:1477-1485. https://doi.org/ 10.3168/jds.S0022-0302(07)71633-8.

van Knegsel, A. T., S. van Der Drift, M. Horneman, A. De Roos, B. Kemp, and E. Graat. 2010. Ketone body concentration in milk determined by Fourier transform infrared spectroscopy: Value for the detection of hyperketonemia in dairy cows. J. Dairy Sci. 93:3065-3069. https://doi.org/10.3168/jds.2009-2847.

van Knegsel, A. T., H. van den Brand, J. Dijkstra, S. Tamminga, and B. Kemp. 2005. Effect of dietary energy source on energy balance, production, metabolic disorders and reproduction in lactating dairy cattle. Reprod. Nutr. Dev. 45:665-688. https://doi.org/ 10.1051/rnd:2005059.

Vicari, T., J. van den Borne, W. Gerrits, Y. Zbinden, and J. Blum. 2008. Postprandial blood hormone and metabolite concentrations influenced by feeding frequency and feeding level in veal calves. 
Domest. Anim. Endocrinol. 34:74-88. https://doi.org/10.1016/j .domaniend.2006.11.002.

West, J. W., B. Mullinix, and J. Bernard. 2003. Effects of hot, humid weather on milk temperature, dry matter intake, and milk yield of lactating dairy cows. J. Dairy Sci. 86:232-242.

Wilmink, J. 1987. Adjustment of test-day milk, fat and protein yield for age, season and stage of lactation. Livest. Prod. Sci. 16:335348.

Wong, H. B., and G. H. Lim. 2011. Measures of diagnostic accuracy: Sensitivity, specificity, PPV and NPV. Proc. Singapore Healthcare $20: 316-318$.
Wu, X., V. Kumar, J. R. Quinlan, J. Ghosh, Q. Yang, H. Motoda, G. J. McLachlan, A. Ng, B. Liu, and S. Y. Philip. 2008. Top 10 algorithms in data mining. Knowl. Inf. Syst. 14:1-37. https://doi .org/10.1007/s10115-007-0114-2.

Xu, W., J. Vervoort, E. Saccenti, R. van Hoeij, B. Kemp, and A. van Knegsel. 2018. Milk metabolomics data reveal the energy balance of individual dairy cows in early lactation. Sci. Rep. 8:15828.

Yegnanarayana, B. 2009. Basics of artifical neural networks. Pages 15-39 in Artificial Neural Networks. PHI Learning Pvt. Ltd., New Delhi, India.

\section{APPENDIX}

\section{Machine Learning Algorithms}

Decision Tree is a decision support model with a tree-like graph presenting decisions and their possible consequences on each node. As one widely used algorithm in Decision Tree (Wu et al., 2008), the C4.5 algorithm constructs subtrees (lower levels of the tree) through recursive partitioning of each sample, choosing the largest information gain ratios in earlier iterations (higher levels of the tree) to divide each instance (Quinlan, 1996). If all remaining instances belong to the same class, then the $\mathrm{C} 4.5$ algorithm stops building subtrees. The information gain (IG) is defined as

$$
\operatorname{IG}(D, a)=\operatorname{Entropy}(D)-\sum_{v=1}^{V} \frac{\left|D^{v}\right|}{|D|} \operatorname{Entropy}\left(D^{v}\right),
$$

where

$$
\operatorname{Entropy}(D)=-\sum_{k=1}^{|y|} p_{k} \log _{2} p_{k}
$$

where $D$ is a sample set with $k$ class; $p_{k}$ is the proportion of example in class $k$; discrete attribute $a$ has $v$ possible values $\mathrm{a}_{1}, \mathrm{a}_{2}, \ldots, \mathrm{a}_{v}$; and $D^{v}$ is a set including all samples with the same $v$ in attribute $a$. There is no setting to parameters "weights" and "subset"; "parms" is "1" (default value); and "method" is "class."

Naïve Bayes is a classification technique based on Bayes' Theorem, where all features are supposed to be independent (Domingos and Pazzani, 1997). Although this assumption rarely holds true in real-world applications, Naïve Bayes still performs well in many cases (Domingos and Pazzani, 1997; Ng and Jordan, 2001), based on Maximum a Posteriori principle:

$$
\hat{y}=\underset{c \in y}{\arg \max } P(c) \prod_{i=1}^{d} P\left(x_{i} \mid c\right),
$$

where $y$ is a set of class $c ; P(c)$ is prior probability; $P\left(x_{i} \mid c\right)$ is class-conditional probability of $x$ in feature $i$ as class $c$; and $d$ is the sum of features. There was no setting to parameters "subset," "na.action," "sampsize," and "threshold," and "laplace" is "0" (default).

Bayesian Network is a probabilistic graphical model developed from Naïve Bayes. In graphical models of Bayesian Network, each node represents a random variable, and the edge between the nodes represents probabilistic dependencies among corresponding random variables. Bayesian Network therefore enables an effective representation and computation of joint probability distribution over a set of random variables (Pearl, 2014). There is no setting to the parameters "dist," "ordinal," and "keep.fitted," and "method" is "bayes-lw."

In Support Vector Machine, each observation is plotted as a point in $n$-dimensional space $(n$ is the number of features in the data set) with the value in a particular coordinate of each feature. Then, separating the classes with a hyperplane maximizes the margin between them. The sample point closest to the hyperplane is termed "support vector" (Hsu et al., 2003). There is no setting to the parameters "subset," "startweights," "lifesign," and "maxnodes"; "tolerance" is "0.001" (default); "epsilon" is "0.1" (default); "cachesize" is " 40 " (default); "degree" is " 3 " (default); "coef0" is " 0 " (default); "shrinking" is "TRUE" (default); and "fitted" is "TRUE" (default).

Artificial Neural Networks consist of interconnected processing units (nodes). Each node consists of a summing part receiving $N$ input values, weights, and bias to compute a weighted sum. The output part produces a signal from the weighted sum (Yegnanarayana, 2009). Processing units process data and learn to recognize linear or nonlinear patterns through iterative learning. There is no setting to the parameters "err.fct," "act. fct," and "exclude"; "likelihood" is "TRUE" (default); "hidden" is "c(5)"; "stepmax" is "1e6"; "threshold" is "0.1"; and "linear.output" is "FALSE." 
Bootstrap Aggregation is a method to generate multiple classifiers to get an aggregated predictor (Breiman, 1996a). Predictors are constructed using bootstrap samples in training data sets and then aggregated to form a Bootstrap predictor. Each bootstrap step leaves out about $37 \%$ of samples as out-of-bag samples for testing (Breiman, 1996b). There is no setting to the parameters "nbagg," "na.action," and "coob," and "method" is "standard."

Random Forest is based on Decision Tree algorithm with a group of tree-structured classification models. In Random Forest, many classifiers are trained using $m$ bootstrap samples from the training data set, which is in line with Bootstrap Aggregation. A subset of features is randomly selected to generate each classifier in Random Forest, whereas Bootstrap Aggregation uses all features (Breiman, 2001; Liaw and Wiener, 2002).
There is no setting to the parameters "subset," "na. action," "sampsize," and "maxnodes"; "mtry" is "3" (default); "nodesize" is "1" (default), "ntree" is "500," and "proximity" is "TRUE."

K-Nearest Neighbor is a widely used nonparametric classifier. It classes tested samples through the distance function built with the training data set and prerequisite parameter K. Euclidean distance is the most widely used distance function for continuous variables in KNN (Hu et al., 2016). Optimal $\mathrm{K}$ is a prerequisite determined by cross-validation. It is a type of instance-based algorithm, where the function is only approximated locally and all computation is deferred until classification; therefore, off-line training is not needed (Tan, 2006). There is no setting to the parameters "prob" and "l," and " $\mathrm{k}$ " is " $10 . "$ 